\title{
Intracranial Endodermal Sinus Tumour - Role for Chemotherapy
}

\author{
Brian A. Anderson
}

\begin{abstract}
Pineal tumours are commonly of germ cell origin. The endodermal sinus tumour is a rare histologic subtype that is highly malignant and radioresistant. A single case is described and compared to six reported intracranial cases in which chemotherapy was used in addition to surgery and/or radiation. Although a beneficial effect of chemotherapy cannot be proven, the probable benefit in non-CNS cases requires that it be strongly considered. A uniform approach to diagnosis, investigation and treatment for intracranial tumours of this type is suggested.
\end{abstract}

\begin{abstract}
RÉSUMÉ: Le rôle de la chimiothérapie dans les tumeurs intracrâniennes du sinus endodermique Les tumeurs de la pinéale originent habituellement de cellules embryonnaires. La tumeur du sinus endodermique est un sous-type histologique qui est très malin et radiorésistant. Nous en décrivons un cas que nous comparons à six autres cas rapportés dans la littérature où la chimiothérapie a été associée à la chirurgie et/ou à la ratiothérapie. Même si on n'a aucune preuve que la chimiothérapie est efficace, ce mode de traitement doit être sérieusement considéré dans ces cas, à cause du bénéfice parfois obtenu dans les cas où la tumeur est située hors du système nerveux central. Nous suggérons une approche uniforme au diagnostic, à l'investigation et au traitement des tumeurs intracrâniennes de ce type.
\end{abstract}

Can. J. Neurol. Sci. 1987; 14:166-171

Tumours of germ cell origin, identical to those occurring in the gonads, are the most common pineal neoplasms.' They may be pure examples or mixtures of different histologic subtypes: germinoma, embryonal carcinoma, choriocarcinoma, endodermal sinus (yolk sac) or teratoma. ${ }^{1-6}$

Certain germ cell tumours, most notably the testicular seminoma, are potentially curable with surgery, radiation and/or chemotherapy. Intracranial germ cell tumours may share the same potential. Few cases of intracranial endodermal sinus tumour where chemotherapy was used in addition to surgery and/or radiation have been reported. This tumour is highly malignant and radioresistant; $;^{5.7 .9,10}$ however, isolated reports have suggested that chemotherapy may improve the prognosis. ${ }^{2.8 .9 .10 .11}$ This report describes a pineal-region endodermal sinus tumour in which chemotherapy was used. Other reported cases where chemotherapy was used are reviewed. Issues in the management of this tumour are discussed.

\section{Case History}

This seventeen year old male had no prior illnesses. He presented with a one month history of increasingly severe headache. Physical examination showed bilateral papilledema, dilated pupils sluggishly reactive to light, and restricted upward conjugate gaze. There were no other abnormal physical findings. Computerized tomographic scan (CT) showed moderate hydrocephalus and an enhancing pineal tumour (Figure 1). Serum human chorionic gonadotropin (HCG) was $2(\mathrm{~N}<5)$ international units per litre (IU/L) and alphafetoprotein (AFP) was 15 $(\mathrm{N}=0-20)$ nanograms per $\mathrm{ml}(\mathrm{ng} / \mathrm{ml})$. Biopsy was not attempted. He was given 5,128 rads whole brain irradiation ( 28 treatments over a 5 week interval). No chemotherapy was given. His condition rapidly improved. He remained asymptomatic with a normal physical examination for the next eight months.

Eight months after diagnosis, he developed headache and lethargy. Physical examination showed bilateral papilledema and a right sixth nerve palsy. CT showed a right frontal, densely enhancing lesion with surrounding edema. There were areas within the lesion of decreased density suggesting necrosis (Figure 2). The pineal region showed no abnormality. At craniotomy, a vascular tumour arising from the base of the brain in the region of the sphenoid ridge was subtotally removed.

Pathological examination showed a tumour with the endodermal sinus histology. There was a loose meshwork of spaces lined by cuboidal cells. Papillary structures compatible with Schiller-Duval bodies were seen (Figure 3). Intracellular periodic acid Schiff-positive globules immunoreactive for alphafetoprotein were present. No other germ cell tumour elements were noted.

The patient improved markedly in the immediate postoperative period. Serum AFP was $1,941 \mathrm{ng} / \mathrm{ml}$. HCG was 2 . Chemotherapy was started. He was given vinblastine $8 \mathrm{mg}$ and cisplatinum $35 \mathrm{mg}$ intravenously on two occasions, twenty-four hours apart. Bleomycin $35 \mathrm{mg}$ was then given intravenously and repeated 24,48 and 72 hours later.

From the Section of Neurology, Department of Medicine, University of Manitoba, Winnipeg

Received September 2. 1986. Accepted in final form February 5, 1987

Reprint requests to: Dr. Brian A. Anderson, St. Boniface General Hospital, 409 Tache Avenue, Winnipeg, Manitoba, Canada R2H 2A6 


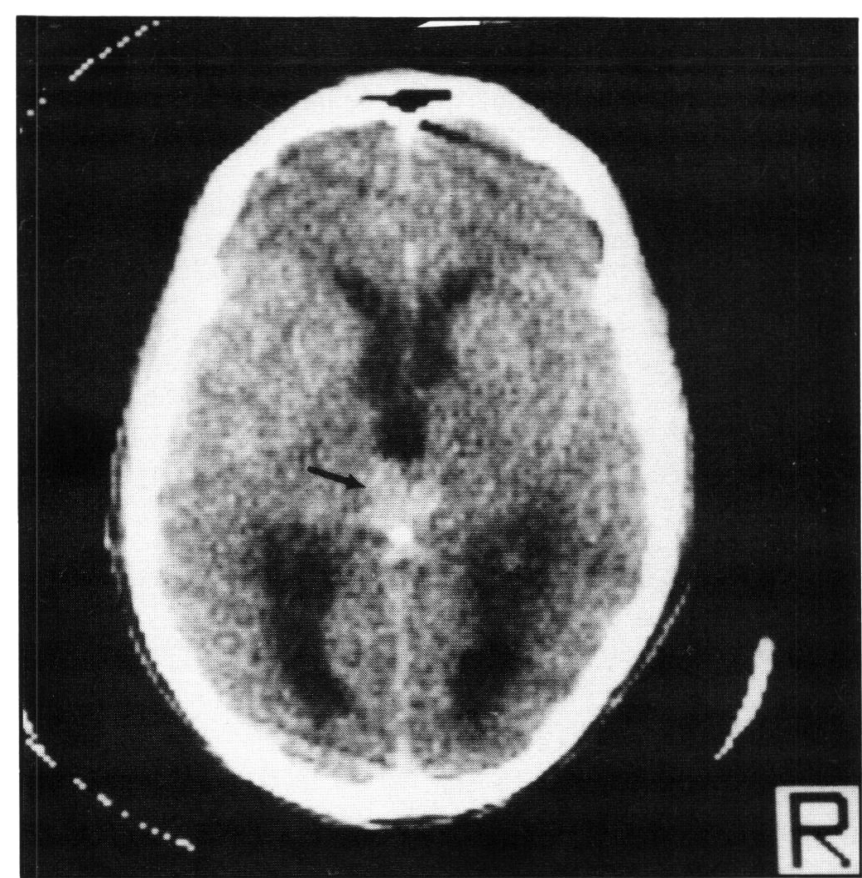

Figure I - Contrast enhanced CT showing pineal-region tumour (arrow).

The patient improved progressively over the next one month. He was then given a further course of chemotherapy (cisplatinum $35 \mathrm{mg}$ on days $1,2,3,4$ and 5 intravenously; vinblastine $5.5 \mathrm{mg}$. on days 1 and 2 intravenously prior to cisplatinum; bleomycin 30 units day 2 prior to vinblastine). AFP at one month was $503 \mathrm{ng} / \mathrm{ml}$.

The patient felt very well. He had no neurological deficit. Further courses of chemotherapy were given on five occasions over the following three months. AFP and HCG were unchanged. A CT ten months after diagnosis showed no evidence of residual tumour.

Despite his return to clinical normality, the patient suddenly collapsed in coma and died within a few hours, twelve months after initial diagnosis. Postmortem brain examination showed diffuse subarachnoid hemorrhage. There was diffuse infiltration of the subarachnoid space by tumour of the endodermal sinus histology. Nodular deposits of tumour were seen throughout the subarachnoid space but were most prominent in the pineal region extending to the right subfrontal area. The subarachnoid hemorrhage had occurred within the vascular tumour in the subarachnoid space. It was considered the mechanism of the patient's death.

\section{DISCUSSION}

We present this seventeen year old male with a pineal tumour. Histological diagnosis was not pursued initially and radiotherapy was given. Eight months later the tumour recurred and was subtotally removed. Pathological examination revealed an endodermal sinus tumour. The patient was then treated with a chemotherapy regimen consisting of cisplatinum, vinblastine and bleomycin. Clinical improvement occurred. CT two months prior to death showed no residual tumour. The serum AFP level was markedly elevated at the time when tumour metastases were detected, and the HCG level was normal. Despite a return to clinical normality, the patient died suddenly one year after diagnosis. Postmortem examination showed disseminated tumour in the subarachnoid space into which subarachnoid hemorrhage had occurred.

The clinical presentation in this case is like many described in the literature. This tumour presents in young people and favours a midline location, most commonly the pineal and suprasellar areas. It is prone to metastasize through the subarachnoid

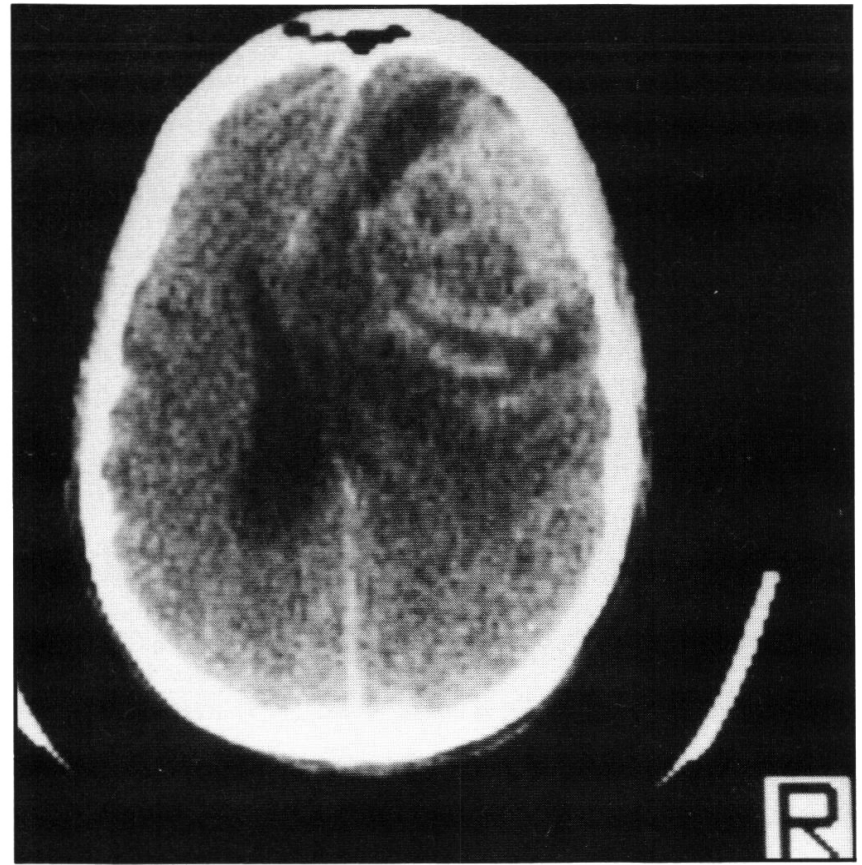

Figure 2 - Contrast enhanced CT eight months after diagnosis showing metastatic tumour in the right frontal region.

space as exemplified by the present case. Hemorrhage into intracranial endodermal sinus tumour has been described in a previous case. ${ }^{12}$ Subarachnoid hemorrhage in relation to subarachnoid space tumour has not been noted previously. ${ }^{13}$

The optimal management of intracranial endodermal sinus tumour has not been established. The tumour tends to occur in deep midline structures making removal and/or biopsy potentially dangerous. This has led to the use of radiotherapy alone. Although in isolated instances prolongation of life has resulted, most reports suggest little benefit. ${ }^{14.15}$

Total or subtotal removal of endodermal sinus tumour occurring outside the CNS is known to favourably influence the outcome, especially when combined with other treatment modalities. $^{8,10,15,16}$ Surgery for pineal-region tumours may be technically difficult or dangerous, but new techniques may allow removal or biopsy. For example, the supratentorial, suboccipital approach may have less morbidity compared to other approaches. ${ }^{17.18}$ Stereotactic biopsy is now possible and offers the opportunity for accurate histologic diagnosis with minimal risk. ${ }^{17}$ However, germ cell tumours are often mixtures of different histologic subtypes. A small biopsy specimen may be misleading. Therefore, conclusions about tumour type are made after considering both histology and tumour marker studies.

The presence of tumour markers in some germ cell tumours may allow noninvasive diagnosis. Embryonal carcinoma, choriocarcinoma and endodermal sinus tumour have this potential. ${ }^{12}$ AFP and HCG elevation have been noted in embryonal carcinoma. HCG elevation alone has been seen with choriocarcinoma. AFP elevation alone has been most commonly associated with endodermal sinus tumour. Pure germ cell tumour (seminoma histology), is not associated with elevations of these markers. There is evidence that serum and cerebrospinal fluid (CSF) levels rise and fall with metastases and in response to treatment. ${ }^{12.16 .19}$ However, levels have been normal in cases with ${ }^{20}$ and without mestastases. ${ }^{21}$ The tumour markers can additionally be of use in pathological diagnosis as they can 
Table 1: Cases of intracranial endodermal sinus tumour treated with chemotherapy

\begin{tabular}{|c|c|c|c|c|}
\hline \multirow[b]{2}{*}{ Case Age } & Patient characteristics & \multirow[t]{2}{*}{ Investigations } & \multirow[t]{2}{*}{ Pathologic diagnosis \& treatment } & \multirow[t]{2}{*}{ Outcome \& Comments } \\
\hline & Sex Presentation \& Clinical Course & & & \\
\hline $\begin{array}{l}1 . \quad 12 \\
\text { (ref. 22) }\end{array}$ & $\begin{array}{l}\text { M -month history of headeache, } \\
\text { nausea, vomiting; exam } \\
\text { showed nonreacting pupils, } \\
\text { disconjugate gaze, (L) } 7 \text { th } \\
\text { nerve palsy, (L) hemiparesis, } \\
\text { bilaterally up-going plantar } \\
\text { responses }\end{array}$ & $\begin{array}{l}\text { At diagnosis: CT scan } \\
\text { showed posterior third } \\
\text { ventricle lesion with } \\
\text { obstructive hydrocephalus }\end{array}$ & $\begin{array}{l}\text { At diagnosis: Suboccipital } \\
\text { craniotomy with partial tumour } \\
\text { removal. Endodermal sinus } \\
\text { histology noted, (?pure). } 4500 \text { rads } \\
\text { whole brain, } 1080 \text { rads to tumour } \\
\text { region, } 3910 \text { rads spinal axis } \\
\text { radiation. Vincristine, actinomy- } \\
\text { cin D, cyclophosphamide regimen } \\
\text { given. }\end{array}$ & $\begin{array}{l}\text { Dramatic clinical improvement } \\
\text { noted at } 3 \text { weeks. Clinical and } \\
\text { radiologic normality at } 12 \\
\text { months. Authors stated their } \\
\text { intention to continue chemo- } \\
\text { therapy for } 24 \text { months. } \\
\text { Eventual outcome not known. }\end{array}$ \\
\hline
\end{tabular}

\section{4 M 3-week history of headache} (ref. 13) and vomiting; exam showed a partial Parinaud's syndrome and early papilledema with no other focal signs.

10 weeks: All symptoms and signs resolved.

5 months: Spastic paraparesis

6 months: Headache, lethargy, nuchal rigidity

10 months: Terminal. Respiratory distress and quadriplegia.
At diagnosis: CT scan showed an enhancing posterior third ventricle mass with obstructive hydrocephalus. Angiogram showed vascular tumour.

10 weeks: CT scan normal

5 months: Myelogram showed $T_{1}-T_{5}$ obstruction by intradural, extramedullary metastases.

6 months: CT scan showed recurrent tumour.
At diagnosis: Ventriculoperitoneal (VP) shunt. No biopsy attempted. 3800 rads whole brain radiation given. Vincristine $1.4 \mathrm{mg}$. weekly $x 6$ weeks and procarbazine $50 \mathrm{mg}$. orally $\mathrm{x} 11$ weeks given.

5 months: Laminectomy $T_{2}-T_{9}$. Vincristine $1.4 \mathrm{mg} . \mathrm{I} . V . \mathrm{x} 4$ weeks. 3000 rads spinal axis and 500 rads tumour site radiation.

6 months: 1950 rads to intracranial recurrent tumour site. Dianhydrogalactitol I.V. (dose not mentioned) $x 5$ days.
Died 10 months after diagnosis. Autopsy showed pineal area and diffuse subarachnoid space infiltration by endodermal sinus tumour. Metastases to the peritoneum via the VP shunt were present.

\section{19 F 2-month history of headache, (ref. 13) \\ nausea, vomiting; exam showed left 3 rd nerve palsy.}

3 months: Ascites.

30 months: Lethargy, CNS sympoms (not specified).
At diagnosis: CT scan showed an enhancing suprasellar mass. Angiography showed vascular tumour. Hypopituatarism. CSF negative for AFP and HCG.

3 months: Paracentesis fluid positive for tumour cells and AFP.
At diagnosis: VP shunt established. Transphenoidal subtotal removal of tumour. 3800 rads whole brain irradiation given. Endodermal sinus histology.

3 months: Vinbastine $6 \mathrm{mg}$. I.V. $\mathrm{x}$ one dose, actinomycin D $1.5 \mathrm{mg}$. I.V. $x$ one dose, cyclophosphamide $900 \mathrm{mg}$. I.V. $x$ one dose, cis-platinum $120 \mathrm{mg}$. I.V. $x$ one dose, bleomycin 30 units daily $x 7$ days. Maintenance chemotherapy with Vinblastine $4 \mathrm{mg} . \mathrm{x} \mathrm{I}$, chlorambucil $4 \mathrm{mg}$. p.o. $x$ 14 doses and actinomycin D $1.5 \mathrm{mg}$. I.V. $x$ one dose; 2 reinductions with the original agents given.

30.months: CT scan showed 30 months: Above chemotherapy recurrent suprasellar tumour.
Alive at 30 months after diagnosis with recurrent suprasellar tumour. 
(Table 1 continued)

\begin{tabular}{lcc}
\hline \hline & \multicolumn{2}{c}{ Patient characteristics } \\
\cline { 2 - 2 } Case & Age & Sex Presentation \& Clinical Course \\
\hline $\begin{array}{l}\text { 4. } 12 \\
\text { (ref. 12) }\end{array}$ & F & $\begin{array}{l}\text { 1-month history of headache, } \\
\text { nausea, vomiting. }\end{array}$
\end{tabular}

\begin{tabular}{|c|c|}
\hline Investigations & Pathologic diagnosis \& treatment \\
\hline
\end{tabular}

CT scan: pineal region enhancing mass with hydrocephalus. Serum and CSF AFP elevated; $\mathrm{HCG}$ normal.
VP shunt. No biopsy performed. 4500 rads whole brain irradiation given at diagnosis. Five months later, additional 3000 rads given to tumour recurrence; 6 months later, 1500 rads whole brain and 3500 rads spinal axis irradiation. Methotrexate $10 \mathrm{mg}$. p.o. every other day after second course of radiation. Vincristine $0.5 \mathrm{mg}$. once weekly $\mathrm{x} 15$ weeks and Bleomycin $10 \mathrm{mg}$. twice weekly $x$ 10 weeks with third course of radiation.

\section{19 F 1-month history of headache, (ref. 16) nausea, vomitting; exam showed papilledema and bilateral 6th nerve palsies.}

2 months: No information. 8 months: headache, nausea, ataxia
CT scan: pineal region mass with obstructive hydrocephalus. Angiography: highly vascular tumour (tumour blush) 2 months: CT scan normal. 8 months: CT scan: pineal region tumour extending forward into suprasellar region and posteriorly below tentorium. AFP elevated in CSF but negative in serum. HCG negative. CSF cytology: tumourcells (histologic type uncertain)

10 months: CT scan: enlargement of previously seen tumour.
At diagnosis: VP shunt. No biopsy attempted. 5050 rads whole brain radiation.

8 months: Biopsy of recurrent tumour in the posterior fossa. $\mathrm{BCNU}$ (?dose) given. Pathologic exam showed pure endodermal sinus tumour.
Initial response to radiotherapy dramatic. No evidence of clinical or radiological response to chemotherapy.
Tumour size decreased with treatments. Total survival following diagnosis was 13 months. Tumour histology (endodermal sinus) postmortem. Postmortem showed large residual tumour in the third ventricle region.

\begin{abstract}
6. $13 \mathrm{M}$ Presentation not reported;
(ref. 27) tumour metastasized to abdomen via VP shunt causing small bowel obstruction.
\end{abstract}

No details given.

At diagnosis: VP shunt. Partial
resection of pineal tumour.
Radiation and chemotherapy
(vincristine, actinomycin and
cyclophosphamide) given. Timing,
dosages are not mentioned. Pure
endodermal sinus histology seen
in biopsy material.

Patient died at 12 months. No postmortem examination reported.
Died at 22 months. Authors felt course of disease not affected by chemotherapy or radiation.

\section{17 M 1 month history of headache: (current exam showed papilledema, case) large, poorly reactive pupils, decreased upgaze. \\ 8 months: lethargy, headache. Exam showed papilledema and? right sixth nerve palsy. \\ At diagnosis: CT scan showed enhancing pineal tumour with moderate hydrocephalus. \\ 8 months: Right frontal densely enhancing lesion with focal hypodense areas suggesting tumour necrosis. Serum AFP elevated; HCG negative.} 9-12 months: Clinically norma
12 months: sudden collapse,
coma, death.
9-12 months: serum AFP and HCG $x$ I determination: unchanged.
At diagnosis: No VP shunt. No biopsy attempted. 4500 rads whole brain radiation.

8 months: Tumour subtotally removed. Pathologic examination showed endodermal sinus tumour. Vinblastine $8 \mathrm{mg}$. I.V. $\times 2$, cisplatinum $35 \mathrm{mg}$. I.V. $\times 2$, bleomycin 35 units I.V. $x 4$ given.

9 months: Vinblastine $5.5 \mathrm{mg}$. I.V. $\times 2$, cis-platinum $35 \mathrm{mg}$. I.V. $\times 5$ and bleomycin 30 units $x 1$.

$10,11,12$ months: Repeat of treatment given at 9 months.
Died 12 months postdiagnosis. Postmortem showed diffuse subarachnoid space infiltration by endodermal sinus tumour. 


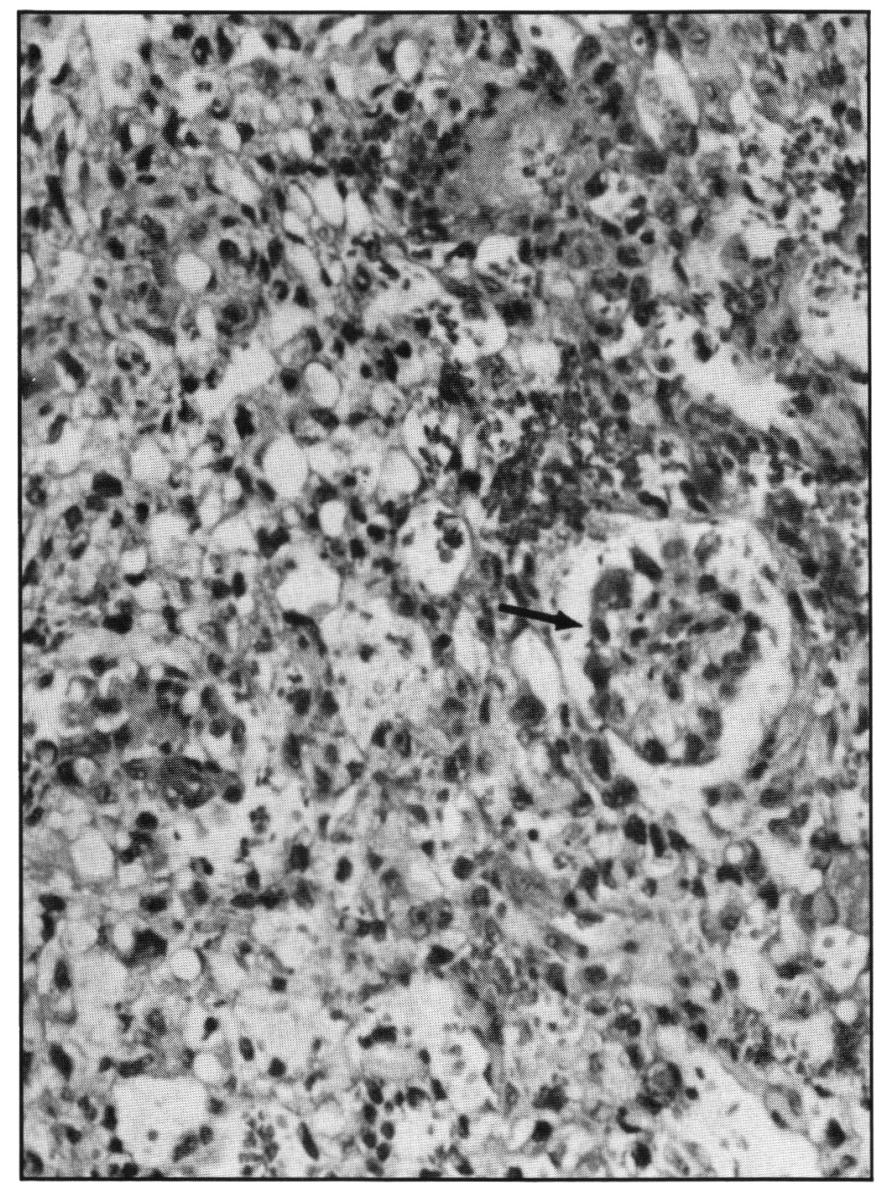

a

Figure 3 - Photomicrograph of endodermal sinus tumour. a) A SchillerDuval body (arrow) is seen within a meshwork of sieve-like spaces. b) A more cellular area of the tumour shows tubular structures lined by cuboidal epithelium. $H$ and $E X 125$.

be detected by immunohistochemical staining. ${ }^{12,19,21,22,23}$

Reports describing the use of chemotherapy in intracranial endodermal sinus tumour are summarized in Table 1. There are seven cases reported in which tumour histology is available and where chemotherapy was given in addition to surgery and/or radiation (present case included). The cases are similar in age distribution. Five cases had pineal-region neoplasms and two had suprasellar tumours. All of the pineal-region neoplasms had a relatively short clinical course prior to diagnosis. The suprasellar neoplasms may have been preceded by endocrine disturbances related to tumour. The clinical presentation was similar in all instances. Histologic diagnosis was obtained at initial presentation in only three cases. Radiotherapy was given as the initial treatment in the remaining cases. In only one case was surgery, radiation and chemotherapy started at initial diagnosis. In all other cases, including the present case, chemotherapy was given when the tumour was known to have metastisized and when further radiotherapy was not feasible. Furthermore, the chemotherapy regimens used were not the same although all with the exception of case 3 used drugs recommended for tumours of germ cell origin. Cases 1 and 3 were alive at the time of reporting, 12 and 30 months after diagnosis respectively. The remaining cases had died 10, 13, 12 and 22 months after diagnosis. Survival beyond that reported for cases treated with surgery and/or radiation alone is not

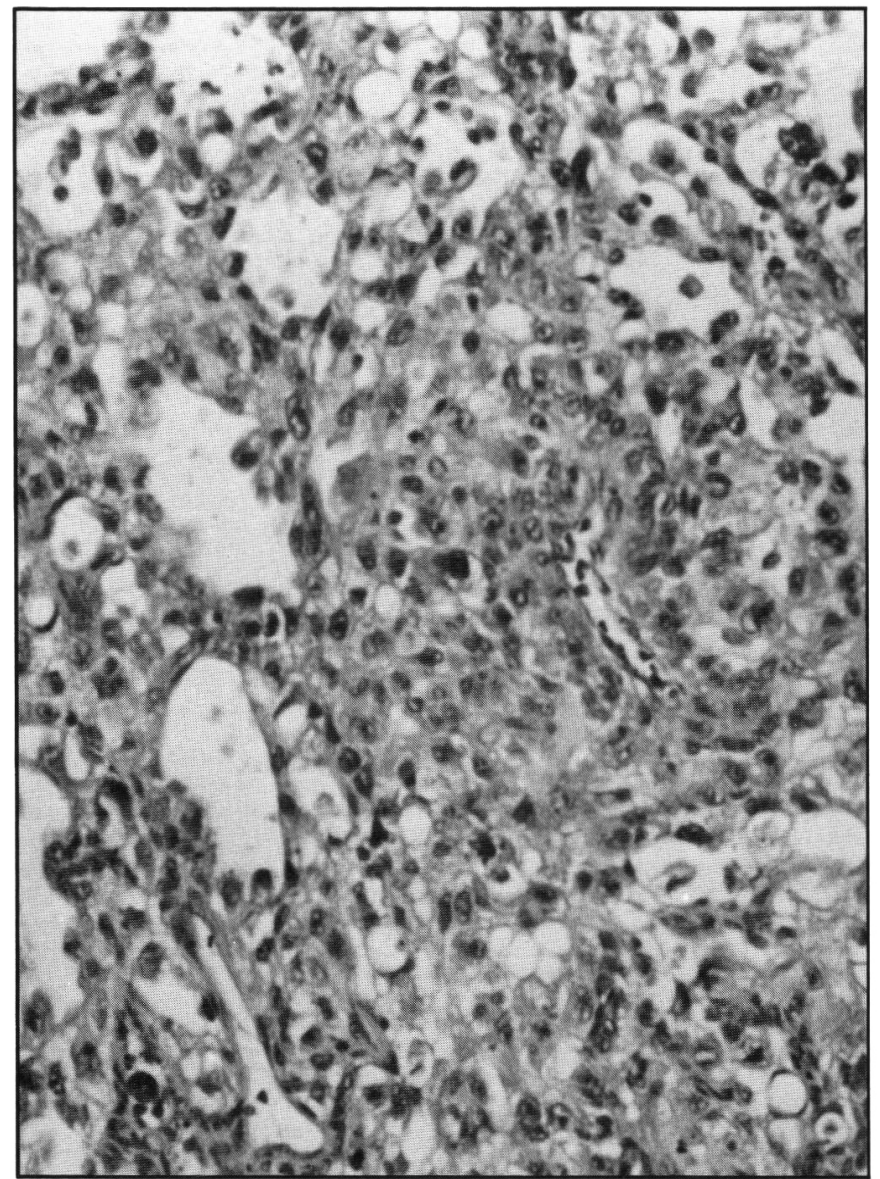

b

suggested. However, in the absence of a uniform approach to diagnosis and treatment, no generalizations or conclusions can be made.

Evidence has accumulated that chemotherapy for nonseminomatous germ cell tumours outside the CNS improves the prognosis for survival. ${ }^{24.25}$ Chemotherapy protocols using cisplatinum, cyclophosphamide, vinblastine and bleomycin have been the most successful. ${ }^{24}$ There is doubt whether chemotherapy influences the course of disseminated non-seminomatous germ cell tumours of the gonads when endodermal sinus histology is predominant, although patients with restricted involvement having endodermal sinus histology are benefited. ${ }^{24}$ The benefit of chemotherapy in non-CNS tumours together with the observation that the effective chemotherapy penetrates CSF and brain parenchyma supports its trial in CNS tumours. ${ }^{23.26}$

In summary, the role for chemotherapy in endodermal sinus tumour restricted to the CNS remains to be clarified. A uniform approach to diagnosis and treatment is required. ${ }^{2}$ All cases should be diagnosed histologically and the tumour removed in whole or in part where possible. Serum and CSF AFP and HCG should be monitored to aid in diagnosis and the detection of metastases. Whole neuraxis radiation and chemotherapy regimens effective against germ cell tumours should be strongly considered. 


\section{REFERENCES}

1. Russell DS, Rubinstein LJ. Pineal tumours. In: Pathology of tumours of the nervous system. Williams and Wilkins 1977; 283-298.

2. Jennings MT, Gelman R, Hochberg F. Intracranial germ-cell tumours: natural history and pathogenesis. J Neurosurg 1985; 63: 155-167.

3. Borit A. Embryonal carcinoma of the pineal region. J Pathol 1969; 97: $165-168$

4. Jellinger K. Primary intracranial germ cell tumours. Acta neuropathologica 1973; 25: 291-306.

5. Murovic JA, Ongley JP, Parker JC, et al. Manifestations and therapeutic considerations in pineal yolk-sac tumours. Case report. J Neurosurg 1981; 55: 303-307.

6. Takei Y, Pearl GS. Ultrastructural study of intracranial yolk sac tumour. Cancer 1981; 48: 2038-2046.

7. Gershenson DM, del Junco G, Herson J, et al. Endodermal sinus tumour of the ovary. Obstet Gynecol 1983; 61: 194-202.

8. Kurman RJ, Norris HJ. Endodermal sinus tumour of the ovary. A clinical and pathologic analysis of 71 cases. Cancer 1976; 38: 2404-2419.

9. Prioleau G, Wilson CB. Endodermal sinus tumour of the pineal region. Case report. Cancer 1976; 38: 2489-2493.

10. Ungerleider RS, Donaldson SS, Warnke RA, et al. Endodermal sinus tumour. The Stanford experience and the first reported case arising in the vulva. Cancer 1978; 41: 1627-1634.

11. Einhorn LH, Donohue J. Cis-diamminedichloroplatinum, vinblastine, and bleomycin combination chemotherapy in disseminated testicular cancer. Ann Intern Med 1977: 87: 293-298.

12. Arita N, Bitoh S, Ushio Y, et al. Primary pineal endodermal sinus tumour with elevated serum and CSF alphafetoprotein levels. Case report. J Neurosurg 1980; 53: 244-248.

13. Wilson ER, Takei Y, Bikoff WT, et al. Abdominal metastases of primary intracranial yolk sac tumours through ventriculoperitoneal shunts: report of three cases. Neurosurgery 1979; 5(3): 356-364.

14. Eberts TJ, Ransberg RC. Primary intracranial endodermal sinus tumour. Case report. J Neurosurg 1979; 50: 246-252.

15. Tavcar D, Robboy SJ, Chapman P. Endodermal sinus tumour of the pineal region. Cancer 1980; 45: 2646-2651.
16. Bamberg M, Metz K, Alberti W, et al. Endodermal sinus tumour of the pineal region. Cancer 1984; 54: 903-906.

17. Pecker J, Scarabin JM, Vallee B, et al. Treatment in tumours of the pineal region: value of stereotaxic biopsy. Surg Neurol 1979; 12: $341-348$.

18. Stein BM. Tumours of the pineal region. In: Youmans JR, ed. Neurological Surgery. WB Saunders 1982; 5: 2863-2871.

19. Schultz H, Sell A, Norgaard-Pedersen B, et al. Serum alphafetoprotein and human chorionic gonadotropin as markers for the effect of postoperative radiation therapy and/or chemotherapy in testicular cancer. Cancer 1978; 42: 2182-2186.

20. Siegal T, Pfeffer R, Catane R, et al. Successful chemotherapy of recurrent intracranial germinoma with spinal metastases. Neurology (Cleveland) 1983; 33: 631-3.

21. Arita N, Ushio Y, Hayakawa T, et al. Serum levels of alphafetoprotein, human chorionic gonadotropin and carcinoembryonic antigen in patients with primary intracranial germ cell tumours. Oncodev Biol Med 1980; 1: 235-240.

22. Bjornsson J, Scheithauer BW, Okazaki H, et al. Intracranial germ cell tumours: pathobiological and immunohistochemical aspects of 70 cases. J Neuropathol Exp Neurol 1985; 44: 32-46.

23. Ginsberg S, Kirshner J, Reich S, et al. System chemotherapy for a primary germ cell tumour of the brain: a pharmacokinetic study. Cancer Treat Rep 1981; 65: 477-483.

24. Logothetis CJ, Samuels ML, Trindade A, et al. The prognostic significance of endodermal sinus tumour histology among patients treated for stage III nonseminomatous germ cell tumours of the testes. Cancer 1984; 53: 122-128.

25. Rusch VW, Logothetis C, Samuels M. Endodermal sinus tumour of the mediastinum. Chest 1984; 86(5): 745-747.

26. Neuwelt EA. Frenkel EP, Smith RG. Suprasellar germinomas (ectopic pinealomas): aspects of immunological characterization and successful chemotherapeutic responses in recurrent disease. Neurosurgery 1980; 7(4): 352-358.

27. Olsen MM, Raffensperger JG, Gonzalez-Crussi F. et al. Endodermal sinus tumour: a clinical and pathological correlation. Journal of Pediatric Surgery 1982; 17(6): 832-838. 